\title{
ASPECTOS LEGAIS ENVOLVIDOS NA COLETA DE DADOS LINGUÍSTICOS
}

Ricardo Nascimento Abreu

\section{INTRODUC̣ÃO}

O processo de coleta de dados para a constituição dos corpora, não só para as pesquisas em linguística, mas para todas as ciências humanas e sociais, está completamente adstrito às mesmas regras éticas que valem para as ciências médicas. Esse sufocamento teve origem após a Segunda Guerra Mundial, dado o estarrecimento da comunidade internacional com as notícias advindas das análises das práticas de "higiene racial" do governo nazista. A decisão de intervir, tutelando os direitos das pessoas submetidas às pesquisas científicas e, principalmente, a necessidade de estabelecer obrigações e responsabilidades para instituições e seus pesquisadores, colocou-se como algo urgente no cenário do pós-guerra. Assim, o Código de Nuremberg (I947), a Declaração Universal dos Direitos Humanos (I948) e a Declaração de Helsinque (I964) surgem, no âmbito do Direito Internacional, como os principais alicerces nos quais se apoiaram as constituições e legislações infraconstitucionais no mundo para fins de regramento ético nas pesquisas envolvendo seres humanos.

No Brasil, a via de entrada desses parâmetros ético-normativos foi o Conselho Nacional de Saúde que, primeiramente através da Resolução n. 196, de Io de outubro de I996, e após, com a Resolução n. 466, de I 2 de dezembro de 2012 - vem estabelecendo os parâmetros éticos da pesquisa envolvendo seres humanos. O caráter excessivamente biomédico dessas resoluções tem despertado, nos 
últimos anos, severas críticas dos pesquisadores das áreas de ciências sociais e humanas, posto que diversos aspectos atinentes às pesquisas dessas áreas não foram contemplados pelas resoluções e, em várias questões, até mesmo foram inviabilizados. Este texto se debruça sobre as principais implicações legais vinculadas às pesquisas nas humanidades, com ênfase na coleta de dados linguísticos em pesquisas que envolvam a participação de seres humanos.

\section{ASPECTOS ÉTICOS E SUA REGULAC̣ÃO NO BRASIL}

Apesar de encontrarmos na história das ciências registros de elaborações que apontavam para o sentido de estabelecer limites aos procedimentos experimentais, somente no alvorecer da segunda metade do século XX é que a comunidade internacional passa a tutelar os direitos dos sujeitos submetidos às pesquisas científicas, bem como as obrigações e responsabilidades das instituições e seus pesquisadores.

O término da Segunda Guerra Mundial trouxe consigo, entre outras questões, um sem-número de alertas para a comunidade científica internacional sobre os experimentos envolvendo seres humanos, realizados pelos nazistas, na busca da chamada "higiene racial". Esses experimentos afrontavam um dos princípios do direito moderno que, naquela ocasião, fortalecia-se cada vez mais: o princípio da dignidade da pessoa humana.

O ano de 1947 ficou marcado na história das ciências pela assinatura do Código de Nuremberg, instrumento do Direito Público Internacional que vinculava os seus signatários a observar, no âmbito dos seus territórios, uma série de procedimentos éticos no que tange ao desenvolvimento de pesquisas nas quais estivessem envolvidos seres humanos. A consolidação dos fundamentos contidos no Código de Nuremberg se deu, sem dúvida, com a assinatura da Declaração Universal dos Direitos Humanos, em I948, que, por sua envergadura e adesão de vários estados, disseminou princípios importantes, insculpidos nas constituições das nações signatárias. A dignidade da pessoa humana, os princípios da igualdade e da liberdade e a inalienabilidade de direitos, tal qual a vida, foram, sem dúvida alguma, os que trouxeram maiores impactos para a normatização internacional das pesquisas científicas no período do pós-guerra.

Outra contribuição da Declaração Universal dos Direitos Humanos que trouxe grande repercussão entre as ciências humanas e sociais no século XX, e principalmente nestas primeiras décadas do século XXI, é o reconhecimento dos direitos das minorias étnicas, nacionais e religiosas, bem como a declaração de existência de direitos culturais e linguísticos inerentes a todas as comunidades humanas. $\mathrm{O}$ 
reconhecimento desses direitos tem possibilitado extrair leituras que transcendam o aspecto biomédico contido nas intenções do Código de Nuremberg.

No Brasil, a porta de entrada das normas internacionais que visavam regular os procedimentos de pesquisa, após sua recepção constitucional, não se deu por intermédio do Poder Legislativo ou pelo Ministério de Ciência e Tecnologia, como poderíamos, inadvertidamente, supor. $\mathrm{O}$ fato de terem o seu nascedouro vinculado às pesquisas médicas envolvendo seres humanos fez com que ficasse a cargo do Ministério da Saúde a regulamentação da questão no país, materializada por meio do seu Conselho Nacional de Saúde, através da Resolução n. I96, de Io de outubro de 1996.

Apesar de não ter sido gerada no seio do Poder Legislativo e não se constituir, portanto, em lei, a Resolução n. I96/96, já no seu preâmbulo, fundamentava-se nas principais declarações e diretrizes internacionais que regulam a matéria e cumpria as disposições dos principais diplomas normativos do país, tais quais a Constituição da República Federativa do Brasil, o Código Civil, o Código Penal, o Estatuto da Criança e do Adolescente, entre outros, o que lhe deu força de norma cogente ${ }^{\mathrm{I}}$.

Um avanço importante trazido pela Resolução n. I96/96 foi a criação da Comissão Nacional de Ética em Pesquisa (CONEP/MS), uma instância colegiada, de natureza consultiva, deliberativa, normativa, educativa, independente e vinculada ao Conselho Nacional de Saúde. Para além da CONEP/MS, foram também criados os Comitês de Ética em Pesquisa, órgãos colegiados que devem ser implementados, preferencialmente, nas instituições que realizam pesquisas envolvendo seres humanos.

Como estava previsto no seu texto preambular, a Resolução n. I96/96 deveria passar por revisões periódicas para que pudesse ser adequada às novas demandas, principalmente na área das tecnologias e das questões éticas. Fruto desse processo de revisão, o Plenário do Conselho Nacional de Saúde, em sua $240^{a}$ reunião ordinária, realizada nos dias I I e I 2 de dezembro de 20 I 2 , aprovou as novas normas regulamentadoras de pesquisas envolvendo seres humanos: a Resolução n. 466, de I 2 de dezembro de 20I2, publicada no Diário Oficial da União em I 3 de junho de $20{ }_{3} 3$ e que revoga, integralmente, as Resoluções CNS I $96 / 96,303 / 2000$ e 404/2008.

Fiel às suas origens, o novo texto mantém-se ainda excessivamente biomédico, mas aponta, em seu item XIII.3, o fato de que as especificidades éticas das pesquisas nas ciências sociais e humanas e de outras que se utilizam de metodologias próprias dessas áreas serão contempladas em resolução complementar, dadas suas particularidades.

I Norma cogente é aquela que constrange a quem se aplica, tornando seu cumprimento obrigatório de maneira coercitiva. 


\section{2. "ÉTICA IGUAL, PESQUISAS DIFERENTES"}

Com esse título, em um texto da sua autoria, publicado no portal Ciência Hoje, o antropólogo e pesquisador Luiz Fernando Dias Duarte, da Universidade Federal do Rio de Janeiro, discutia, antes mesmo de entrar em vigor a Resolução n. 466/I 2 , a situação das ciências sociais e humanas e apontava a grande dissonância com o texto da resolução mãe, a n. 196/96, no que tange às especificidades dessas ciências.

Concebida precipuamente para lidar com as situações de pesquisa na área médica (e suas tecnologias), a resolução acabou se propondo a regular todas as pesquisas envolvendo 'seres humanos', mesmo aquelas cujas características nada têm de tecnológicas ou interventivas, como as da sociologia, da psicologia (não experimental) e da antropologia. Uma rede de Comitês de Ética em Pesquisa (CEP), subordinados a uma Comissão Nacional de Ética em Pesquisa (CONEP) vinculada ao Ministério da Saúde, foi criada em todo o país com atribuições universais de controle e fiscalização dos projetos de pesquisa. (DUARTE, 2009).

Ainda segundo Duarte (2009), essa seria uma temática de solução relativamente simples, caso fosse realizada a distinção entre os termos pesquisa $\mathrm{em}$ seres humanos e pesquisa com seres humanos. Enquanto as ciências médicas realizam, na maioria dos casos, pesquisas em seres humanos, de caráter interventivo, as demais ciências humanas e sociais realizam pesquisas com seres humanos, sem lhes afetar diretamente as condições de saúde, a incolumidade física ou quaisquer outros aspectos de natureza biológica.

Atualmente, a Associação Brasileira de Antropologia (ABA), com o aval da Associação Nacional de Pós-Graduação e Pesquisa em Ciências Sociais (ANPOCS) e de várias associações representantes das diversas áreas da pesquisa em ciências sociais e humanas, a exemplo da Associação Nacional de PósGraduação e Pesquisa em Letras e Linguística (ANPOLL), vem, através de um Grupo de Trabalho constituído também por membros da CONEP/MS, discutindo e delineando o documento que complementará a Resolução n. 466/I 2 nos aspectos que lhes forem pertinentes. Apesar dos avanços, as associações têm sido unânimes em alertar para o fato de que uma resolução complementar, vinculada à Resolução n. 466/I 2, como propõe essa norma, manterá as ciências humanas e sociais em uma situação de descabida subordinação às ciências médicas, tolhendo-lhes a autonomia metodológica. Desse modo, paralelamente ao fato de se elaborar um documento que seja capaz de normatizar as pesquisas nas humanidades, o Grupo de Trabalho vem tentando desvincular as suas normas éticas do âmbito do Ministério da Saúde para o Ministério da Ciência e Tecnologia, com a criação de comitês específicos para avaliar e autorizar os projetos de pesquisa oriundos dessas áreas do conhecimento. 


\section{ASPECTOS LEGAIS ENVOLVIDOS NA COLETA DE DADOS LINGUÍSTICOS}

Em Linguística, muito embora não de forma exclusiva, os métodos de coleta de dados para a constituição dos corpora para as pesquisas frequentemente demandam o contato entre o pesquisador e indivíduos ou comunidades. Neste texto, focalizamos exclusivamente essa tipologia de coleta, relacionando-a às implicações legais à luz dos principais diplomas normativos do ordenamento jurídico brasileiro, bem como da própria Resolução n. 466/ I 2 do Ministério da Saúde que, como já dissemos, apesar de não ser uma lei, tem valor de norma cogente.

Preliminarmente, conforme o preâmbulo da Resolução n. 466/I 2 apresenta, toda e qualquer pesquisa (entre elas a pesquisa linguística) deverá ter em mente os Princípios Fundamentais e os Direitos e Garantias Individuais elencados pela Constituição da República Federativa do Brasil, com destaque para a cidadania, a dignidade da pessoa humana, a igualdade e a vedação a toda e qualquer prática discriminatória que atente para esses direitos.

Uma grande diferença entre as Resoluções I96/96 e 466/I 2 diz respeito ao fato de que, na primeira, havia a declaração das principais leis brasileiras que deveriam ser observadas pelo pesquisador no curso da sua pesquisa envolvendo seres humanos; na última, apenas a Constituição é explicitamente citada e os demais diplomas foram substituídos pela expressão "Considerando a legislação brasileira correlata e pertinente".

O texto da Resolução n. 466/I2, por sua vez, apresenta traços marcantes de várias leis brasileiras. Entretanto, nos interessam, de forma mais pontual, as menções ao Código Civil Brasileiro, ao Estatuto da Criança e do Adolescente, ao Estatuto do Idoso, bem como ao Código de Defesa do Consumidor.

O cuidado do linguista, em processo de coleta de dados, em relação ao Código Civil Brasileiro, deve focar principalmente no que concerne à produção de danos aos sujeitos participantes da pesquisa. Assim temos, conforme os artigos n. I 86 e I 87 da Lei n. I0.406, de Io de janeiro de 2002:

Art. I 86 CC - Aquele que, por ação ou omissão voluntária, negligência ou imprudência, violar direito e causar dano a outrem, ainda que exclusivamente moral, comete ato ilícito. Art. I 87 CC - Também comete ato ilícito o titular de um direito que, ao excedê-lo, excede manifestamente os limites impostos pelo seu fim econômico ou social, pela boa-fé ou pelos bons costumes.

Entre outras questões que possam ocorrer, a atenção ao cumprimento desses dois artigos do Código Civil na coleta de dados linguísticos remonta diretamente à aceitação explícita dos participantes da pesquisa, não se admitindo a 
participação tácita. Há, ainda, a necessidade de observação do sigilo dos dados coletados e, principalmente, a proteção das identidades dos participantes. Esse aspecto é bem elucidado no próprio documento do Conselho Nacional de Saúde quando, no item V.7, prevê:

Os participantes da pesquisa que vierem a sofrer qualquer tipo de dano resultante de sua participação na pesquisa, previsto ou não no Termo de Consentimento Livre e Esclarecido, têm direito à indenização, por parte do pesquisador, do patrocinador e das instituições envolvidas nas diferentes fases da pesquisa. (CONSELHO NACIONAL DE SAÚDE, 20 г2).

O Código de Defesa do Consumidor (CDC) traz uma contribuição importantíssima na proteção dos indivíduos e dos grupos que são submetidos às pesquisas de qualquer área do conhecimento, inclusive linguística, com a noção de vulnerabilidade. Pode até nos causar certo estranhamento a utilização do CDC às pesquisas que não se configuram relações de consumo; o fato é que o CDC apenas empresta a noção de vulnerabilidade para ser aplicada às relações entre as instituições, pesquisadores e os sujeitos pesquisados.

Essa noção de vulnerabilidade também está fortemente presente no Estatuto da Criança e do Adolescente e no Estatuto do Idoso, que colocam a criança, o adolescente e o idoso como naturalmente vulneráveis. No caso da Resolução n. 466/I 2, a vulnerabilidade é característica intrínseca dos sujeitos participantes da pesquisa.

A eticidade da pesquisa implica em:

- respeito ao participante da pesquisa em sua dignidade e autonomia, reconhecendo sua vulnerabilidade, assegurando sua vontade de contribuir e permanecer, ou não, na pesquisa, por intermédio de manifestação expressa, livre e esclarecida (CONSELHO NACIONAL DE SAÚDE, 2or 2, grifo nosso).

Para além desses diplomas normativos que já elucidamos, a própria Resolução n. 466/I 2 elenca um conjunto de fundamentos éticos e científicos pertinentes que devem ser obedecidos na condução de coleta de dados pelos pesquisadores. Vejamos:

As pesquisas, em qualquer área do conhecimento envolvendo seres humanos, deverão observar as seguintes exigências:

- ser adequada aos princípios científicos que a justifiquem e com possibilidades concretas de responder a incertezas;

- estar fundamentada em fatos científicos, experimentação prévia e/ou pressupostos adequados à área específica da pesquisa; 
- ser realizada somente quando o conhecimento que se pretende obter não possa ser obtido por outro meio;

- buscar sempre que prevaleçam os benefícios esperados sobre os riscos e/ou desconfortos previsíveis;

- utilizar os métodos adequados para responder às questões estudadas, especificando-os, seja a pesquisa qualitativa, quantitativa ou quali-quantitativa;

- se houver necessidade de distribuição aleatória dos participantes da pesquisa em grupos experimentais e de controle, assegurar que, a priori, não seja possível estabelecer as vantagens de um procedimento sobre outro, mediante revisão de literatura, métodos observacionais ou métodos que não envolvam seres humanos;

- obter consentimento livre e esclarecido do participante da pesquisa e/ou seu representante legal, inclusive nos casos das pesquisas que, por sua natureza, impliquem justificadamente, em consentimento a posteriori;

- contar com os recursos humanos e materiais necessários que garantam o bem-estar do participante da pesquisa, devendo o(s) pesquisador(es) possuir(em) capacidade profissional adequada para desenvolver sua função no projeto proposto;

- prever procedimentos que assegurem a confidencialidade e a privacidade, a proteção da imagem e a não estigmatização dos participantes da pesquisa, garantindo a não utilização das informações em prejuízo das pessoas e/ou das comunidades, inclusive em termos de autoestima, de prestígio e/ou de aspectos econômico-financeiros;

- ser desenvolvida preferencialmente em indivíduos com autonomia plena. Indivíduos ou grupos vulneráveis não devem ser participantes de pesquisa quando a informação desejada possa ser obtida por meio de participantes com plena autonomia, a menos que a investigação possa trazer benefícios aos indivíduos ou grupos vulneráveis;

- respeitar sempre os valores culturais, sociais, morais, religiosos e éticos, como também os hábitos e costumes, quando as pesquisas envolverem comunidades;

- garantir que as pesquisas em comunidades, sempre que possível, traduzir-se-ão em benefícios cujos efeitos continuem a se fazer sentir após sua conclusão. Quando, no interesse da comunidade, houver benefício real em incentivar ou estimular mudanças de costumes ou comportamentos, o protocolo de pesquisa deve incluir, sempre que possível, disposições para comunicar tal benefício às pessoas e/ou comunidades;

- comunicar às autoridades competentes, bem como aos órgãos legitimados pelo Controle Social, os resultados e/ou achados da pesquisa, sempre que estes puderem contribuir para a melhoria das condições de vida da coletividade, preservando, porém, a imagem e assegurando que os participantes da pesquisa não sejam estigmatizados;

- assegurar aos participantes da pesquisa os benefícios resultantes do projeto, seja em termos de retorno social, acesso aos procedimentos, produtos ou agentes da pesquisa;

- utilizar o material e os dados obtidos na pesquisa exclusivamente para a finalidade prevista no seu protocolo, ou conforme o consentimento do participante; (CONSELHO NACIONAL DE SAÚDE, 2012 , grifo nosso). 


\section{DO PROCESSO DE CONSENTIMENTO LIVRE E ESCLARECIDO}

Ponto fulcral do texto da Resolução n. 466/I 2 diz respeito ao Processo de Consentimento Livre e Esclarecido. O respeito ao princípio da dignidade da pessoa humana exige que toda pesquisa se processe com consentimento livre e esclarecido dos participantes, indivíduos ou grupos que, por si e/ou por seus representantes legais, manifestem a sua anuência à participação no procedimento.

Entende-se por Processo de Consentimento Livre e Esclarecido o procedimento através do qual o sujeito convidado a participar de uma pesquisa seja devidamente elucidado acerca das etapas a serem percorridas, para que possa se manifestar, de forma autônoma, consciente, livre e esclarecida. Essa etapa da coleta de dados sofreu modificações em relação ao texto normativo da Resolução n. I96/96 por conta de pressões advindas principalmente dos pesquisadores das ciências humanas e sociais que - enfrentando aquilo que Labov (2008) chamou, na Sociolinguística, de paradoxo do observador - tinham as suas pesquisas prejudicadas pelo fato de contaminar a coleta de dados por conta da necessidade de obtenção prévia do Termo de Consentimento Livre e Esclarecido.

A etapa inicial do Processo de Consentimento Livre e Esclarecido é a do esclarecimento ao convidado a participar da pesquisa, ocasião em que o pesquisador, ou pessoa por ele delegada e sob sua responsabilidade, deverá:

- buscar o momento, condição e local mais adequados para que o esclarecimento seja efetuado, considerando, para isso, as peculiaridades do convidado a participar da pesquisa e sua privacidade;

- prestar informações em linguagem clara e acessível, utilizando-se das estratégias mais apropriadas à cultura, faixa etária, condição socioeconômica e autonomia dos convidados a participar da pesquisa; $\mathrm{e}$

- conceder o tempo adequado para que o convidado a participar da pesquisa possa refletir, consultando, se necessário, seus familiares ou outras pessoas que possam ajudá-los na tomada de decisão livre e esclarecida. (Conselho Nacional de Saúde, 20I2).

Superada a etapa inicial de esclarecimento, o pesquisador responsável, ou pessoa por ele delegada, deverá apresentar ao convidado para participar da pesquisa, ou a seu representante legal, o Termo de Consentimento Livre e Esclarecido para que seja lido e compreendido, antes da concessão do seu consentimento livre e esclarecido. Nele, obrigatoriamente deverão estar contidos:

- justificativa, os objetivos e os procedimentos que serão utilizados na pesquisa, com o detalhamento dos métodos a serem utilizados, informando a possibilidade de inclusão em grupo controle ou experimental, quando aplicável; 
- explicitação dos possíveis desconfortos e riscos decorrentes da participação na pesquisa, além dos benefícios esperados dessa participação e apresentação das providências e cautelas a serem empregadas para evitar e/ou reduzir efeitos e condições adversas que possam causar dano, considerando características e contexto do participante da pesquisa;

- esclarecimento sobre a forma de acompanhamento e assistência a que terão direito os participantes da pesquisa, inclusive considerando benefícios e acompanhamentos posteriores ao encerramento e/ ou a interrupção da pesquisa;

- garantia de plena liberdade ao participante da pesquisa, de recusar-se a participar ou retirar seu consentimento, em qualquer fase da pesquisa, sem penalização alguma;

- garantia de manutenção do sigilo e da privacidade dos participantes da pesquisa durante todas as fases da pesquisa;

- garantia de que o participante da pesquisa receberá uma via do Termo de Consentimento Livre e Esclarecido;

- explicitação da garantia de ressarcimento e como serão cobertas as despesas tidas pelos participantes da pesquisa e dela decorrentes; e

- explicitação da garantia de indenização diante de eventuais danos decorrentes da pesquisa. (CONSELHO NACIONAL DE SAÚDE, 20I 2)

O Termo de Consentimento Livre e Esclarecido deverá, ainda:

- conter declaração do pesquisador responsável que expresse o cumprimento das exigências contidas no item IV. 3 da Resolução n. 466/I 2 ;

- ser aprovado pelo CEP perante o qual o projeto foi apresentado e pela CONEP, quando pertinente; e

- ser elaborado em duas vias, rubricadas em todas as suas páginas e assinadas, ao seu término, pelo convidado a participar da pesquisa, ou por seu representante legal, assim como pelo pesquisador responsável, ou pela (s) pessoa (s) por ele delegada (s), devendo as páginas de assinaturas estar na mesma folha. Em ambas as vias deverão constar o endereço e contato telefônico ou outro, dos responsáveis pela pesquisa e do CEP local e da CONEP, quando pertinente. (CONSELHO NACIONAL DE SAÚDE, 20I2).

Por fim, a Resolução n. 466/I 2 trata dos indivíduos em restrição da liberdade ou do esclarecimento necessário para o adequado consentimento: em pesquisas nas quais a coleta de dados é realizada com crianças e adolescentes, estudantes, militares, presidiários e pessoas relativamente ou absolutamente incapazes, na acepção do Código Civil, ou ainda nos casos em que os agrupamentos humanos estejam submetidos à líderes religiosos ou de outra natureza, como também, no caso dos índios, cuja submissão ao ato autorizativo prévio é para a FUNAI.

- em pesquisas cujos convidados sejam crianças, adolescentes, pessoas com transtorno ou doença mental ou em situação de substancial diminuição em sua capacidade de decisão, deverá haver justificativa clara de sua escolha, especificada no protocolo e aprovada pelo 
CEP, e pela CONEP, quando pertinente. Nestes casos deverão ser cumpridas as etapas do esclarecimento e do consentimento livre e esclarecido, por meio dos representantes legais dos convidados a participar da pesquisa, preservado o direito de informação destes, no limite de sua capacidade;

- a liberdade do consentimento deverá ser particularmente garantida para aqueles participantes de pesquisa que, embora plenamente capazes, estejam expostos a condicionamentos específicos, ou à influência de autoridade, caracterizando situações passíveis de limitação da autonomia, como estudantes, militares, empregados, presidiários e internos em centros de readaptação, em casas-abrigo, asilos, associações religiosas e semelhantes, assegurando-lhes inteira liberdade de participar, ou não, da pesquisa, sem quaisquer represálias;

- em comunidades cuja cultura grupal reconheça a autoridade do líder ou do coletivo sobre o indivíduo, a obtenção da autorização para a pesquisa deve respeitar tal particularidade, sem prejuízo do consentimento individual, quando possível e desejável.

Quando a legislação brasileira dispuser sobre competência de órgãos governamentais, a exemplo da Fundação Nacional do Índio - FUNAI, no caso de comunidades indígenas, na tutela de tais comunidades, tais instâncias devem autorizar a pesquisa antecipadamente. (CONSELHO NACIONAL DE SAÚDE, 2012).

Nos casos em que é inviável a obtenção do Termo de Consentimento Livre e Esclarecido ou que sua obtenção signifique riscos substanciais à privacidade e confidencialidade dos dados do participante ou aos vínculos de confiança entre pesquisador e pesquisado, a sua dispensa deve ser justificadamente solicitada pelo pesquisador responsável ao Sistema CEP/CONEP, para apreciação, sem prejuízo do posterior processo de esclarecimento.

\section{RECOMENDAC̣ÕES FINAIS}

A coleta de dados para constituição de corpora para pesquisas em linguística, bem como nas demais ciências humanas e sociais, está subordinada às questões ético-legais constantes em diplomas normativos brasileiros, além de estar diretamente vinculada às normas emanadas pelo Conselho Nacional de Saúde, através da Resolução n.466 de I 2 de dezembro de 20 I 2.

O direcionamento biomédico que historicamente consta nas resoluções vem despertando movimentos, no interior das humanidades, no sentido de que sejam criadas normas específicas e que, para além disso, ocorra a criação de um Conselho de Ética para analisar as pesquisas das ciências humanas e sociais, no seio do Ministério da Ciência e Tecnologia, e não do Ministério da Saúde, conforme o modelo atualmente vigente. 
Apesar de constar na Resolução n. 466/I 2 um dispositivo que autoriza a elaboração de uma resolução complementar que atenda às especificidades das ciências sociais e humanas, não significa que essas ciências não devam obedecer aos preceitos constantes do texto principal. A atenção aos princípios constitucionais da dignidade da pessoa humana, da cidadania, dos valores sociais e da vedação ao preconceito devem sempre nortear a coleta de dados que envolvam diretamente seres humanos.

\section{REFERÊNCIAS}

CONSELHO NACIONAL DE SAÚDE. Resolução n. I96, de io de outubro de 1996. Dispõe sobre diretrizes e normas regulamentadoras de pesquisas envolvendo seres humanos. Disponível em: <http://conselho.saude.gov.br/web_comissoes/conep/aquivos/resolucoes/ resolucoes.htm>. Acesso em: 02 fev. 20I4. CONSELHO NACIONAL DE SAÚDE. Resolução n. 466 , de I2 de dezembro de $20 \mathrm{I} 2$. Dispõe sobre diretrizes e normas regulamentadoras de pesquisas envolvendo seres humanos. Disponível em: <http://conselho.saude.gov.br/resolucoes/20I 2/Reso466.pdf>. Acesso em: Io fev. 20I4.

BRASIL. Constituição (1988). Contêm as emendas constitucionais posteriores. Brasília, DF: Senado, 20I3.

DUARTE, L. F. D. Ética igual pesquisas diferentes. Instituto Ciência Hoje, set 2009. Disponível em: <http://cienciahoje.uol.com.br/colunas/sentidos-do-mundo/etica-igual-pesquisas-diferentes $>$. Acesso em: fev. 2014 . 
